\title{
Unusual Presentation of a Rare Cancer: Histiocytic Sarcoma in the Brain 16 Years After Treatment for Acute Lymphoblastic Leukemia
}

Sreelatha Chalasani, MD; Mark R. Hennick, MD; William G. Hocking, MD; Gene R. Shaw, MD; and Benjamin Lawler, MD

Histiocytic sarcoma (HS) is a very rare hematopoietic neoplasm that has been reported in association with other hematological malignancies. Presentation of HS in the central nervous system is even less common. Diagnosis of HS requires the presence of histiocytic markers and the systematic exclusion of markers of other cell lineages. Primary HS central nervous system tumors are aggressive and generally have poor outcomes. There are no standard treatment guidelines due to lack of clinical trials and a limited number of case reports. Here we present a unique case with two primary histiocytic lesions in the brain, refractory to systemic and radiation therapies, that developed after being treated for T-cell acute lymphoblastic leukemia 16 years prior.

Keywords: Acute lymphoblastic leukemia; Central nervous system; Histiocytic sarcoma

Corresponding Author: Sreelatha Chalasani, MD

Department of Internal/Hospital Medicine Marshfield Clinic

1000 North Oak Avenue

Marshfield Wisconsin 54449

Tel: (715) 387-5537

Fax: (7I5) 389-5757

Email: chalasani.sreelatha@marshfieldclinic.org

Received: April 27, 2012

Revised: July 20, 2012

Accepted: July 25, 2012

doi: $10.3121 / \mathrm{cmr} .2012 .1092$
$\mathrm{H}$

istiocytic sarcoma (HS) is a rare neoplasm composed of tumor cells derived from the monocyte/macrophage lineage. Involvement of the central nervous system in HS is rare and usually aggressive, ${ }^{1}$ and it can be difficult to diagnose. There are several reports of HS in association with hematological malignancies. Here we present a unique case of a man with histiocytic sarcoma in the brain, refractory to systemic and radiation therapies, that developed 16 years after treatment for T-cell acute lymphoblastic leukemia (T-ALL).

\section{Case Presentation}

A male patient, age 44 years, presented to the emergency room with unsteadiness, loss of balance, and left-sided weakness of 2 weeks duration. The patient had been evaluated in the emergency room for confusion a few days earlier, which was attributed to excessive use of lorazepam for panic attacks. He was subsequently seen by his primary care physician who obtained a computerized tomography (CT) scan and magnetic resonance imaging (MRI) of the brain that showed two intra-axial enhancing lesions: one in the corpus callosum of $3.5 \mathrm{~cm}$, and the other adjacent to the right lateral ventricle of $2.6 \mathrm{~cm}$, both associated with vasogenic edema (figure 1).

The patient had been diagnosed with T-ALL with cerebrospinal fluid (CSF) involvement 16 years prior and had received craniospinal irradiation and intrathecal chemotherapy for approximately 26 months. After completion of T-ALL treatment, he had no significant health problems other than anxiety and panic attacks for which he took buspirone, paroxetine, and lorazepam. The 


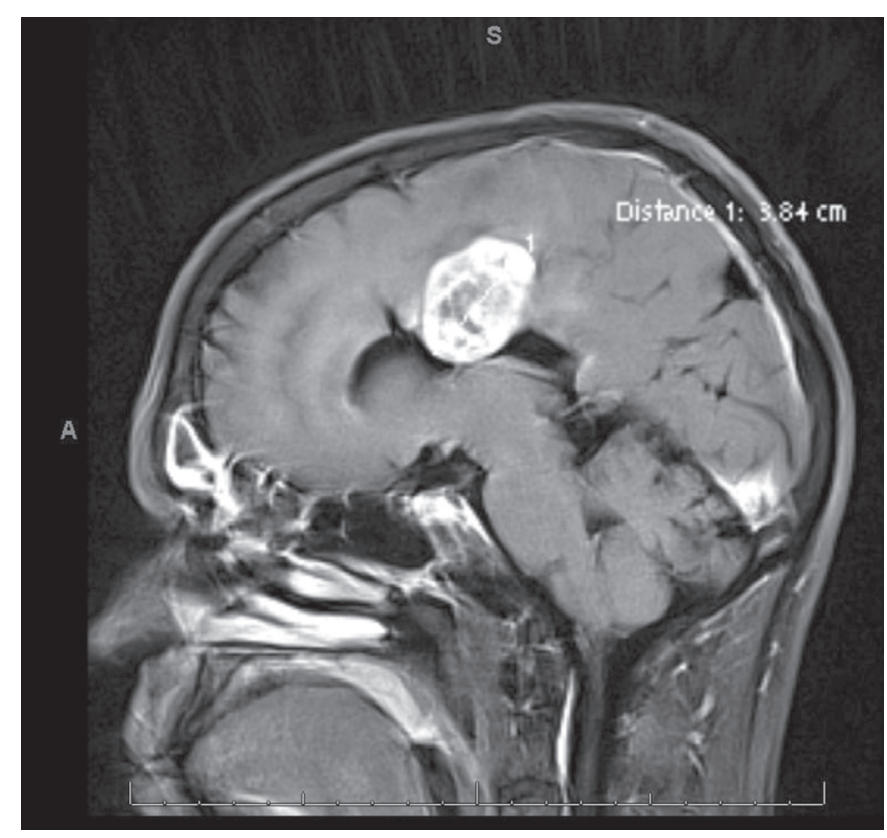

Figure 1. Magnetic resonance imaging of the brain showing one of two intra-axial enhancing lesions.

patient did not smoke, but reported drinking six to eight beers per day. Review of systems was otherwise negative.

Vital signs were stable; cardiac, abdominal, and respiratory examinations were normal. On neurologic examination, the patient was found to be neglectful of his left side on dual simultaneous stimulation. He was oriented and cranial nerve exam was normal; however, he had mild left hemiparesis and hemiapraxia.

Complete blood count, comprehensive metabolic panel, thyroid stimulating hormone, vitamin $\mathrm{B}_{12}$ levels, and international normalized ratio were all normal. The CSF was negative for acid fast bacilli (AFB), fungal cultures, and cryptococcal antigen, and CSF cell count analysis showed 3 nucleated cells and 2 red blood cells $/ \mu \mathrm{L}$. White blood cell differential was $8 \%$ neutrophils, $12 \%$ lymphocytes, $78 \%$ monocytes, and $2 \%$ basophils. Glucose was $77 \mathrm{mg} / \mathrm{dL}$, and CSF protein was $25 \mathrm{mg} / \mathrm{dL}$. Positron emission tomography (PET) scan findings were consistent with the MRI and CT scans. There were no hypermetabolic lesions within the remaining visualized portion of the body to suggest a potential source of metastatic disease.

The patient was treated with dexamethasone to decrease the edema and levetiracetam to prevent seizures. He was also given multivitamins, vitamin $\mathrm{B}_{12}$, folic acid, and thiamine because of his chronic alcohol use. A stereotactic biopsy of the right parietal brain tumor was obtained. The biopsy contained a dense infiltrate of abnormally large cells with irregular nuclear outlines, hyperchromatic nuclei, and abundant eosinophilic cytoplasm upon hematoxylin and eosin (H\&E) stain (figure 2A). Tumor cells were positive for monocyte/macrophage markers CD11c (figure 2B), CD68 (both PGM1 and KP-1), CD163 (figure 2C), and lysozyme by immunoperoxidase staining. Markers of T-cells, B-cells, glial cells, dendritic cells, anaplastic large cell lymphoma, melanocytes, neurons, and epithelial cells were all negative (CD3, CD20, CD45, S-100, CD30, CD1a, GFAP, LFB/ PAS, ALK neurofilament, and cytokeratin). The final pathological diagnosis was atypical histiocytic infiltrate consistent with histiocytic sarcoma. Evaluation for T-cell receptor and immunoglobulin gene rearrangements by polymerase chain reaction was attempted on formalin fixed, embedded tissue from the brain lesion. No amplified products (clonal or polyclonal) were observed, and no genetic link between the patient's HS and prior T-ALL could be established.

The patient was treated with $8 \mathrm{~g} / \mathrm{m}^{2}$ intravenous methotrexate and discharged. One week later he received a second dose of $8 \mathrm{~g} / \mathrm{m}^{2}$ methotrexate. Following discharge, his condition worsened clinically and radiographically, and he exhibited progressive left hemiparesis. He was then treated with 2600 cGy of whole brain radiotherapy, with an additional 2000 cGy boost to each lesion. He received temozolomide $150 \mathrm{mg} / \mathrm{m}^{2}$ for five consecutive days during the whole brain radiotherapy. An MRI following whole brain radiotherapy, but before focal boost, showed no change in the size of either tumor. Following radiotherapy, the patient was clinically stable initially, but declined to continue treatment. He was enrolled in hospice and died 4 months later, 27 weeks after initial presentation.

\section{Discussion}

First described by Mathé et $\mathrm{al}^{2}$ in 1970, HS is a rare, but aggressive hematopoietic neoplasm. The World Health Organization currently defines HS as a neoplastic proliferation with morphological and immunophenotypic features of mature tissue histiocytes. ${ }^{3}$ Reactive histiocytic infiltrates and other malignancies, particularly B-cell and T-cell lymphomas, need to be carefully excluded. Prognosis is generally poor due to rapid progression and poor response to therapy.

While HS has been associated with a number of hematological malignancies, ${ }^{4,5}$ including ALL, ${ }^{6-15}$ the risk factors for it are unknown. In some cases, the histiocytic lesions have been shown to share molecular genetic or cytogenetic features with the original leukemia or lymphoma, which may represent transdifferentiation. ${ }^{13}$ Feldman et al ${ }^{4}$ noted seven cases of HS following follicular lymphoma and found both malignancies to be positive for the $t(14 ; 18)$ translocation in all of the patients, suggesting a common clonal origin. Similarly, Castro et $a l^{13}$ and Kumar et $a{ }^{15}$ described cases in which the leukemic and histiocytic lesions shared identical immunoglobulin B-cell or T-cell receptor gene rearrangements. Unfortunately, it was not possible to determine if our patient's HS shared any phenotypic or genetic features with the previously diagnosed T-ALL. It is interesting to note that prior to this report, the longest time span reported between ALL and HS was 14 years. ${ }^{12}$ Our patient was diagnosed with HS 16 years after T-ALL. 
In addition to HS, several other secondary malignancies are associated with ALL, and the 15-year cumulative estimate of secondary malignancies in ALL survivors ranges from $2.5 \%$ to $4 \%$, reaching approximately $6 \%$ at 30 years. ${ }^{16}$ The most common secondary malignancies include central nervous system (CNS) tumors, particularly meningiomas and gliomas, but also primitive neuroectodermal tumors and CNS lymphomas, in addition to leukemias/lymphomas, and skin cancers. Many secondary malignancies are thought to be treatment related, especially in the case of CNS tumors and cranial radiation, but chemotherapy may play a role as well. ${ }^{16}$ Several histiocytic lesions besides HS are also observed following ALL, including the malignant Langerhans' cell sarcoma. ${ }^{13}$

Clinical presentation of HS depends largely on the organ involved, most commonly the intestine, skin, spleen, lymph nodes and bone marrow. ${ }^{2,17,18}$ Patients may be asymptomatic or may present with a mass and symptoms related to compression of surrounding organs. ${ }^{19,20}$ In our case, the presenting symptoms were related to the brain masses. Although tumors in the CNS are one of the more common secondary malignancies occurring in the context of ALL, lymphoproliferative disorders of the CNS are quite rare. ${ }^{16}$ As discussed, the patient did experience CSF involvement and received intrathecal chemotherapy during treatment for T-ALL 16 years prior. In immunocompetent patients, primary CNS lymphomas are quite rare. ${ }^{21}$ While MRI and CT imaging studies are useful for visualizing tumors within the CNS, brain biopsy is generally required for definitive diagnosis. In most cases, surgical resection is ruled out due to location of the tumor. Patients are typically treated with irradiation and corticosteroids in addition to intravenous methotrexate and/or leucovorin, ${ }^{22}$ although optimal treatment remains unclear. ${ }^{23}$

Histiocytic sarcoma is derived from cells of the monocyte/ macrophage lineage. The cells are non-cohesive, large (diameter of $>20 \mu \mathrm{m}$ ), and have abundant eosinophilic cytoplasm. Nuclei are large, pleomorphic, and eccentric with one or more distinct nucleoli and vesicular chromatin. The cytoplasm may contain vacuoles and occasionally has a foamy or xanthomatous appearance. ${ }^{9}$ Some tumors may contain aprominentinflammatory infiltrate, hemophagocytosis, and/or increased mitotic activity. ${ }^{9,19,20}$ While the histological features first described by Mathé et $\mathrm{al}^{2}$ remain important, greater emphasis is currently placed on immunohistochemical and genetic features for diagnosis. ${ }^{20}$ Characteristically, HS tumors express one or more histiocytic markers including CD68, lysozyme, CD163 and CD11c, and do not express B-cell, T-cell, or myeloid markers. Dendritic cell, epithelial, and melanocytic neoplasm markers should also be excluded. ${ }^{19,20}$

There are no extensive case series of HS in the CNS, but there have been sporadic reports. ${ }^{1,24-30}$ Most cases of HS in the CNS have been treated with surgery, chemotherapy, and/or radiation therapy; overall, however, prognosis has been poor despite intensive treatment. Based on this and other cases reported in the literature, the median survival for HS in the CNS is 5 months. ${ }^{1,24,25,27,28,30}$ The cases reported by Cao et $\mathrm{al}^{26}$ and Bell et $\mathrm{a}^{29}$ are the only ones reported to date to maintain a clinically indolent course following local resection and/or radiation therapy.

There is no standard therapy for HS due to the rarity of the disease. Treatment is based on the location and extent of the tumor. Multisystem disease or tumors $>3.5 \mathrm{~cm}$ carry the worst prognosis. ${ }^{20}$ Surgical resection and adjuvant radiation therapy are preferred in localized disease, ${ }^{19}$ while combination chemotherapy (ie, CHOP, ICE, or thalidomide) has been suggested for more aggressive or multifocal presentations. ${ }^{31-35}$ In the present case, combined treatment with methotrexate, temozolomide, and whole brain irradiation with focal boosts to each lesion did not reduce the tumor size, and the patient died 27 weeks after initial presentation.

\section{Conclusion}

In summary, we present a unique case with two primary histiocytic lesions in the brain, refractory to systemic and radiation therapies, that developed after being treated for T-ALL 16 years prior. Histiocytic sarcoma is a very rare malignant neoplasm, and presentation in the CNS is even less
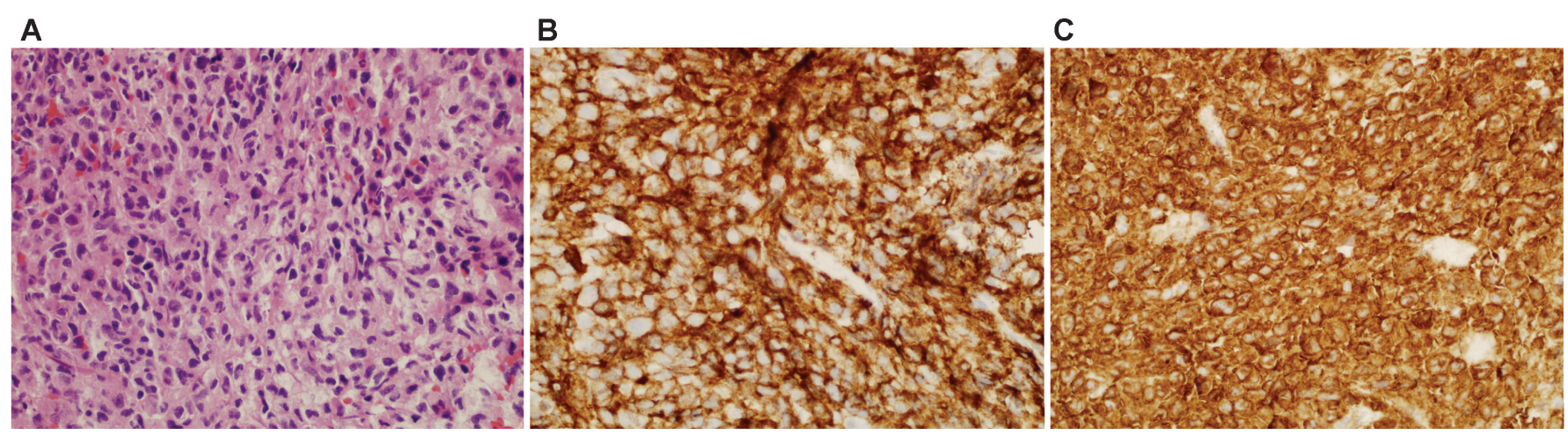

Figure 2. Sections from biopsy of the right parietal brain tumor. (A) H\&E stain showing a dense infiltrate of abnormally large cells with irregular nuclear outlines, hyperchromatic nuclei and abundant eosinophilic cytoplasm (X400). (B) Immunoperoxidase stain for monocyte/macrophage marker CD11c (X400). (C) Immunoperoxidase stain for monocyte/macrophage marker CD163 (X400). 
common. Several reports of HS following hematologic malignancies have been described, even many years after leukemia or lymphoma remission, and this may be a significant history to note. A diagnosis of HS requires the presence of histiocytic markers and the systematic exclusion of markers of other cell lineages. Primary HS CNS tumors are aggressive and generally have poor outcomes. There are no standard treatment guidelines due to lack of clinical trials and a limited number of case reports.

\section{Acknowledgements}

The authors thank the Marshfield Clinic Research Foundation's Office of Scientific Writing and Publication for assistance in the preparation of this manuscript.

\section{References}

1. Sun W, Nordberg ML, Fowler MR. Histiocytic sarcoma involving the central nervous system: clinical, immunohistochemical, and molecular genetic studies of a case with review of the literature. Am J Surg Pathol 2003;27:258-265.

2. Mathé G, Gerard-Marchant R, Texier JL, Schlumberger JR, Berumen L, Paintrand M. The two varieties of lymphoid tissue "reticulosarcomas", histiocytic and histioblastic types. Br J Cancer 1970;24:687-695.

3. Swerdlow S, Campo E, Lee Harris N, et al, eds. WHO Classifcation of Tumours of Haematopoietic and Lymphoid Tissue. Lyon, France: IARC; 2008.

4. Feldman AL, Arber DA, Pittaluga S, Martinez A, Burke JS, Raffeld M, Camos M, Warnke R, Jaffe ES. Clonally related follicular lymphomas and histiocytic/dendritic cell sarcomas: evidence for transdifferentiation of the follicular lymphoma clone. Blood 2008;111:5433-5439.

5. Wang E, Papalas J, Hutchingson CB, Kulbacki E, Huang Q, Sebastian S, Rehder C, Silbermins D, Moore J, Datto M. Sequential development of histiocytic sarcoma and diffuse large B-cell lymphoma in a patient with a remote history of follicular lymphoma with genotypic evidence of a clonal relationship: a divergent (bilineal) neoplastic transformation of an indolent B-cell lymphoma in a single individual. Am J Surg Pathol 2011;35:457-463.

6. van der Kwast TH, van Dongen JJ, Michiels JJ, Hooijkaas H, Kappers MC, Hagemeijer A. T-lymphoblastic lymphoma terminating as malignant histiocytosis with rearrangement of immunoglobulin heavy chain gene. Leukemia 1991;5:78-82.

7. Soslow RA, Davis RE, Warnke RA, Cleary ML, Kamel OW. True histiocytic lymphoma following therapy for lymphoblastic neoplasms. Blood 1996;87:5207-5212.

8. Bouabdallah R, Abéna P, Chetaille B, Aurran-Schleinitz T, Sainty D, Dubus P, Arnoulet C, Coso D, Xerri L, Gastaut JA. True histiocytic lymphoma following B-acute lymphoblastic leukaemia: case report with evidence for a common clonal origin in both neoplasms. Br J Haematol 2001; 113:1047-1050.

9. Pileri SA, Grogan TM, Harris NL, Banks P, Campo E, Chan JK, Favera RD, Delsol G, De Wolf-Peeters C, Falini B, Gascoyne RD, Gaulard P, Gatter KC, Isaazson PG, Jaffe ES, Kluin P, Knowles DM, Mason DY, Mori S, Müller-Hermelink HK, Piris MA, Ralfkiaer E, Stein H, Su IJ, Warnke RA, Weiss LM. Tumours of histiocytes and accessory dendritic cells: an immunohistochemical approach to classification from the International Lymphoma Study Group based on 61 cases. Histopathology 2002;41:1-29.
10. Dalle JH, Leblond P, Decouvelaere A, Yakoub-Agha I, Preudhomme C, Nelken B, Mazingue F. Efficacy of thalidomide in a childe with histiocytic sarcoma following allogeneic bone marrow transplantation for T-ALL. Leukemia 2003;17:2056-2057.

11. Feldman AL, Minniti C, Santi M, Downing JR, Raffeld M, Jaffe ES. Histiocytic sarcoma after lymphoblastic leukaemia: a common clonal origin. Lancet Oncol 2004;5:248-250.

12. Dictor M, Warenholt J, György C, Månsson I, Larsson G. Clonal evolution to histiocytic sarcoma with BCR/ABL rearrangement 14 years after acute lymphoblastic leukemia. Leuk Lymphoma 2009;50:1892-1895.

13. Castro EC, Blazquez C, Boyd J, Correa H, de Chadarevian JP, Felgar RE, Graf N, Levy N, Lowe EJ, Manning JT Jr, Proytcheva MA, Senger C, Shayan K, Sterba J, Werner A, Surti U, Jaffe R. Clinicopathologic featuers of histiocytic lesions following ALL, with a review of the literature. Pediatr Dev Pathol 2010;13:225-237.

14. McClure R, Khoury J, Feldman A. Clonal relationship between precursor B-cell acute lymphoblastic leukemia and histiocytic sarcoma: A case report and discussion in the context of similar cases. Leuk Res 2010;34:e71-e73.

15. Kumar R, Khan SP, Joshi DD, Shaw GR, Ketterling RP, Feldman AL. Pediatric histiocytic sarcoma clonally related to precursor B-cell acute lymphoblastic leukemia with homozygous deletion of $C D K N 2 A$ encoding p16INK4A. Pediatr Blood Cancer 2011;56:307-310.

16. Ng AK, Kenney LB, Gilbert ES, Travis LB. Secondary malignancies across the age spectrum. Semin Radiat Oncol 2010;20:67-78.

17. Marshall ME, Farmer ER, Trump DL. Cutaneous involvement in malignant histiocytosis. Case report and review of the literature. Arch Dermatol 1981;117:278-281.

18. Lahoti NG, Natarajan A, Karuna R, D’Souza RE. Cutaneous histiocytic lesions: a clinical dilemma. J Postgrad Med 2000;46:275-277.

19. Hornick JL, Jaffe ES, Fletcher CD. Extranodal histiocytic sarcoma: clinicopathologic analysis of 14 cases of a rare epithelioid malignancy. Am J Surg Pathol 2004; 28:1133-1144.

20. Vos JA, Abbondanzo SL, Barekman CL, Andriko JW, Miettinen M, Aguilera NS. Histiocytic sarcoma: a study of five cases including the histiocyte marker CD163. Mod Pathol 2005;18:693-704.

21. Fine HA, Mayer RJ. Primary central nervous system lymphoma. Ann Intern Med 1993;119:1093-1104.

22. Deangelis LM, Hormigo A. Treatment of primary central nervous system lymphoma. Semin Oncol 2004;31:684-692.

23. Ricard D, Idbaih A, Ducray F, Lahutte M, Hoang-Xuan K, Delattre JY. Primary brain tumours in adults. Lancet 2012;379:1984-1996.

24. Torres CF, Korones DN, Powers JM, Vadasz AG. Primary leptomeningeal histiocytic lymphoma in a young child. Med Pediatr Oncol 1996;27:547-550.

25. Cheuk W, Walford N, Lou J, Lee AK, Fung CF, Au KH, Mak LS, Chan JK. Primary histiocytic lymphoma of the central nervous system: a neoplasm frequently overshadowed by a prominent inflammatory component. Am J Surg Path 2011;25:1372-1379.

26. Cao M, Eshoa C, Schultz C, Black J, Zu Y, Chang CC. Primary central nervous system histiocytic sarcoma with relapse to mediastinum: a case report and review of the literature. Arch Pathol Lab Med 2007;131:301-305.

27. Gentzler RD, Kahn D. Histiocytic sarcoma: a case of a 52-yearold female with two synchronous primary malignancies at presentation. The Medicine Forum 2009;11:31-33.

28. Toshkezi G, Edalat F, O'Hara C, Delalle I, Chin LS. Primary intramedullary histiocytic sarcoma. World Neurosurg 2010;74:523-527. 
29. Bell SL, Hanzely Z, Alakandy LM, Jackson R, Stewart W. Primary meningeal histiocytic sarcoma: a report of two unusual cases. Neuropathol Appl Neurobiol 2012;38:111-114.

30. Devic P, Androdias-Condemine G, Streichenberger N, Berger F, Honnorat J, Broussolle E, Thobois S. Histiocytic sarcoma of the central nervous system: a challenging diagnosis. QJM 2012;105:77-79.

31. Coiffier B, Lepage E, Briere J, Herbrecht R, Tilly H, Bouabdallag R, Morel P, Van Den Neste E, Salles G, Gaulard P, Reyes F, Lederlin P, Gisselbrecht C. CHOP chemotherapy plus rituximab compared with $\mathrm{CHOP}$ alone in elderly patients with diffuse large-B-cell lymphoma. N Engl J Med 2002;346:235-242.

32. Abidi MH, Tove I, Ibrahim RB, Maria D, Peres E. Thalidomide for the treatment of histiocytic sarcoma after hematopoietic stem cell transplant. Am J Hematol 2007;82:932-933.

33. Gergis U, Dax H, Ritchie E, Marcus R, Wissa U, Orazi A. Autologous hematopoietic stem-cell transplantation in combination with thalidomide as treatment for histiocytic sarcoma: a case report and review of the literature. J Clin Oncol 2011;29:e251-e253.

34. Gisselbrecht C, Glass B, Mounier N, Singh Gill D, Linch DC, Trneny M, Bosly A, Ketterer N, Shpilberg O, Hagberg H, Ma $\mathrm{D}$, Brière J, Moskowitz CH, Schmitz N. Salvage regimens with autologous transplantation for relapsed large B-cell lymphoma in the rituximab era. J Clin Oncol 2010; 28:4184-4190.

35. Mainardi C, D'Amore ES, Pillon M, Toffolutti T, Rosolen A. A case of resistant pediatric histiocytic sarcoma successfully treated with chemo-radiotherapy and autologous peripheral blood stem cell transplant. Leuk Lymphoma 2011; 52:1367-1371.

\section{Author Affiliations}

Sreelatha Chalasani, MD*; Mark R. Hennick, MD*; William G. Hocking, MD*; Gene R. Shaw, MD*;

Benjamin Lawler, MD\$

*Department of Internal/Hospital Medicine, Marshfield

Clinic, Marshfield, Wisconsin, USA

'Department of Hematology/Oncology, Marshfield Clinic, Marshfield, Wisconsin, USA

:Department of Laboratory Pathology, Marshfield Clinic, Marshfield, Wisconsin, USA

sDepartment of Neurology, Marshfield Clinic,

Marshfield, Wisconsin, USA 